\title{
Connecting Storytelling and Social Wellness: A Case for Holistic Storytelling in the Elementary Classroom
}

\author{
Rachel Tinckler
}

\begin{abstract}
Storytelling has a fundamental place in teaching practice, most noticeably in the sharing and developing of curricular content. But teachers share more than academic content with children. A critical prerequisite for meaningful, engaged learning is a strong sense of community and social wellness in the classroom. Based on an inquiry into literature and reflection on personal practice, this study asserts that the practice of storytelling fosters social wellness in the classroom and supports the healthy development of each child as a whole human being within and as part of that community. Connecting storytelling and social wellness, this inquiry offers a unique definition of "holistic storytelling."
\end{abstract}

\section{Storytelling and Social Wellness}

I have always been mesmerized by story. A few precious dusty, worn volumes of tales from my childhood still claim their rightful space on the bookshelves of my adulthood. Occasionally when I turn through their pages, decades melt and the inner feelings of childhood bubble forth from some fountain of memory inside me. What is most magical though is that it is not the text that I read and remember, but rather the sound of my mother's voice I hear. In fact, the books are just the artefacts of my lived experience with storytelling. Just as important as the content of the story was the cadence and tone of the voice that told the story, and my connection to those lived moments were deep and sincere.

To this day, storytelling still has the power to captivate me. While I have a love too for written text, it is the pairing of story and voice that still charms and enthrals me. Perhaps this is why now, in my professional life as an elementary school teacher, I hold storytelling as a fundamental and revered tenet of my pedagogical work with children. Storytelling has tremendous power to form, strengthen, and maintain our sense of self, our perception of others, and our sense of community.

In fact, storytelling has its roots in the very foundations of our humanity and human beings have told stories as long as we have had voice. Sherman (2008) suggests that storytelling is one of the oldest human activities, possibly as old as language itself (p. xvii). Storytelling is a fundamental sharing of the human experience, and each of us shares a multitude of stories every day. The oral tradition of storytelling in particular weaves across all cultures and civilizations and throughout our human history. Sherman further asserts that the pull of story is universal. There is no known culture, Sherman suggests, without some form of storytelling, and the craving to know what comes next is felt by every human being (p. xvii). 
Similarly, Leeming and Sader (1997) state that storytelling is a defining characteristic of human beings where we are united in a universal attempt to understand ourselves (p. 3).

Storytelling is ubiquitous in our educational experiences as well, with teachers drawing on a wide variety of storytelling in support of creating learning experiences with children. For example, storytelling can be used in the classroom to support all aspects of literacy learning (Agosto, 2013; Davies, 2007). However, the power of story extends well beyond its use as a curricular vessel or literacy strategy. Story is infused in the very essence of curriculum and can serve as a means of leading children into curricular topics, and each unit of study can be approached as a story to be told (Egan, 1986).

A somewhat lesser explored use of storytelling is that of therapeutic or healing storytelling, in which story is used with a specific intention of providing some form of healing or health giving. This kind of storytelling is more often seen in the field of therapy and counselling (Carlson \& Arthur, 1999; Land, 2007; Parker \& Wampler, 2006). In addition, this same manner of storytelling is prominent in the realm of Waldorf education, where it is also referred to as "pedagogical storytelling" (Burrows, 2013; Perrow, 2008; Schwartz, 1997, 1999).

While these examples above highlight how storytelling is successfully used in a wide variety of pedagogical and therapeutic practices, my own inquiry lies in the exploration of storytelling as a rich, human experience and the ways in which that richness of story and connection to human experience can bring support to both individual children and the community as a whole. My inquiry draws from all aspects of storytelling with the fundamental perspective that teachers share far more than academic, curricular content with children each day. Critical for meaningful engagement in learning is a strong sense of social wellness among children and with their teacher. This study asserts that the practice of storytelling fosters social wellness and cohesion in the classroom community and supports the healthy development of each child as a whole human being within that community.

For the purposes of this research, storytelling is defined as the practice of sharing a story aloud to a live audience of listeners without the aid or intermediary of a book. It is a direct communication and shared, lived experience between teller and listener. This research assumes the position of teller is the teacher in an elementary classroom, so that she is the one to tell stories with intention to support the wellness of child and community alike. Critical to this study is the perception of each child in the classroom as a whole human being. Therefore, the term child (or children) is used to represent a holistic view of the child, as opposed to student, which speaks more specifically to a child in his or her learning capacities. Specifically, a holistic child perspective sees the whole child, her connection to the natural world, and the spirituality of each child (Hanckel \& Segal, 2016). Finally, the term social wellness, while taken up in more detail later in the discussion, refers to a person's positive sense of self and well-being as well as positive interactions and reciprocity with others in a healthy community.

To explore the connection between storytelling and social wellness in the elementary classroom, in this 
article I first look at a definition of social wellness and its place in a classroom of children. I then consider the positive impact storytelling has on the individual child within the classroom. Next, I turn to the impact storytelling has on the classroom community as a whole. Following, I present a definition of holistic storytelling grounded in the connection between storytelling and social wellness. Finally, I share a perspective on my own personal experience with storytelling in the elementary classroom.

\section{A Praxis Inquiry}

I conducted this inquiry as a practicing teacher hoping to investigate the place of storytelling in supporting children's well-being that could be used by teachers in elementary classrooms. The primary motivation for my research comes from a deep belief that $\mathrm{I}$, as an elementary school teacher, bring more than intellectual, academic learning to my work with children each day. In fact, children need to feel a sense of wellness in their selves and in their community before they can truly open themselves to meaningful learning. Therefore, I continually strive in my teaching practice to support children not just in their learning, but also more holistically as developing young persons, helping to provide them with skills and perspectives that support their overall wellness. In addition, I do not view a class of students as just an amalgamation of individuals. A class is rather a community and the health of that community has a direct impact on each of its members.

One of my own repeating pedagogical themes continues to be storytelling. In my life as a teacher, I have been strongly attracted to the power of story, both in delivering and supporting curricular content and, more broadly, as a means of exploring common experiences together. I have used story to inspire love of reading, introduce content and context, integrate curricular topics, support student writing, build empathy and resilience, and stimulate imagination. The use of story has been a foundation of my teaching philosophy in every teaching position I have held and has been a constant source of teaching inspiration for me throughout my years as a teacher. Recently, I have come to develop and explore the place and importance of storytelling in fostering children's sense of wellness in the classroom, and this wondering became the centre of my inquiry research.

\section{Conceptual Framework}

Personally, I am an anthropologist at heart: I am innately drawn to observe human experiences and behaviours, exploring both the differences and shared conditions of being human. This is true in my teaching life as well, where I have a deep interest in children as young human beings, and understanding each child's unique complexities helps me honour each one more fully.

The conceptual framework for this study is grounded in a constructivist-pragmatic worldview (Creswell, 2014). This research is constructivist in that it was formed in the assumption that human beings construct their own meaning as they engage in and make sense of the world around them, particularly through social interactions (Creswell, 2014). A strong motivation in this research is about seeking understanding. 
In addition, a pragmatic lens has been used in this research in that the research is occurring in context, and the truth is what works at a given time, thus creating a real-world practice-oriented approach (Creswell, 2014).

The concept of holism is also a fundamental, underlying assumption in this research. Holism holds the perspective of looking at an object as a whole, rather than its fragmented parts (Verschuren, 2001). Verschuren further offers than the concept of holism "is important for understanding and maintaining the steady state or equilibrium of a system. In general not the sum of the individual parts of a system makes up an equilibrium, but the integrated whole of these parts" (p. 400). Similarly, Ratner (2008) describes holism as a theory that regards "individuals or elements as reciprocally influencing each other" (p. 513). Therefore, the concept of holism is a very appropriate lens for this study as it supports my two-fold conviction of the child as a whole and the classroom community as an integrated whole. In this article, I assert that such holistic perspectives provide wisdom and insight that can be meaningfully extended and easily taken up in the field of education.

\section{Thematic Review: A Reflection on an Evolving Process}

The questions that arose out of my praxis inquiry motivated me to move beyond my classroom experience with children and into themes of storytelling and wellness in the educational literature. Specifically, the data for this research was collected in a thematic review of the literature, including scholarly journal articles, websites, and publications, related to ideas of storytelling and primarily in the field of education, and elementary education in particular. In addition, given the connection I set out to explore between storytelling and wellness, my thematic review drew also from interdisciplinary fields, including health care, counselling, business, and postsecondary education.

To further frame my research, I draw also from the use of social wellness in postsecondary environments (University of Calgary, n.d.; University of New Hampshire, n.d.; University of California at Riverside, n.d.; University of California at Davis, n.d.), and build my own connections between the concepts of storytelling and social wellness. In connecting these two concepts, I identify the positive influence storytelling has on both individual children and the community of children as a whole. Finally, I offer a definition of holistic storytelling and suggest how this type of storytelling can find its way into every teacher's practice.

\section{Social Wellness in the Classroom}

Social wellness is a concept that is growing in use and attention. At present, the promotion of social wellness is most evident on the campuses of colleges and universities across North America, as well as in the realm of life coaching services, where it is intended to promote wellness for its students. Most broadly, the term wellness encapsulates general good health and a sense of well-being in one's life (Schwartz, 2013). Thus, social wellness begins with this basic premise of wellness and expands into a 
two-fold definition to encompass both self and others (University of Calgary, n.d.; University of New Hampshire, n.d.; University of California at Riverside, n.d.; University of California at Davis, n.d.). Social wellness arises from the idea that well-being in one's life comes from both a positive sense of self and positive sense of belonging. Expressed another way, I offer that social wellness is experienced when the $I$ is healthy and well, and the $I$ is healthy and well in its interactions with others.

Using information from a variety of postsecondary institutions (University of Calgary, n.d.; University of New Hampshire, n.d.; University of California at Riverside, n.d.; University of California at Davis, n.d.) and my own synthesizing, some essential components are outlined below to provide a working definition of social wellness. Social wellness is present when an individual is able to:

- Display respect for self and others, including an appreciation for diversity;

- Exhibit self-confidence;

- Process emotional experiences in healthy ways;

- Display resilience;

- Demonstrate self-advocacy skills;

- Cultivate and maintain a positive sense of personal identity;

- Build, choose, and maintain positive, healthy relationships;

- Effectively communicate with others;

- Offer and receive friendship;

- Manage conflict in positive, healthy ways;

- Create and maintain positive, healthy boundaries with others.

While notions of social wellness are being taken up predominantly with adult audiences at present, the components that make up good social wellness are the very things that we as teachers address every day in the classroom. With adults, aspects of social wellness can be explicitly named and worked with metacognitively. That is, we adults can often very easily think about our thinking and make intentional changes. This language and the process of such self-actualizing is a bit beyond the self-reflective capacities of children, but that is not to say that children do not understand the ideas behind the language. They do very deeply. In fact, the notions of social wellness are fundamentally what we teach and work to instil in children every day: having a positive sense of self, interacting positively with others, and seeing oneself as a positive, contributing member of a community. Children may not have the language that I use here, but fundamentally children know when they feel right in themselves and know when they feel connected to those around them. Children have an innate drive to seek and maintain social wellness.

Fundamentally, social wellness has two essential aspects: wellness in regard to self and wellness in regard to community. For a child to experience a sense of social wellness, both criteria need to be met. In this inquiry, I proffer that storytelling in the classroom supports the positive development of social wellness in both of these aspects: it supports a child's sense of self as well as a sense of community for the whole. I present evidence for both of these claims in the following two sections. 


\section{Storytelling and the Child}

As Carlson and Arthur (1999) assert, every child is continually striving to become a well-adjusted human being. If we hold this perspective in teaching, this reminds us to see the whole child and not just a few selected aspects such as a behaviour or difficulty. Our work with every child can be in support of this striving, especially with the use of storytelling in the classroom. In conducting my thematic review, I developed the conviction that storytelling supports the wellness of each child in three specific ways, including: promoting her capacity for emotional processing and resilience, making personal meaning, and cultivating personal connections. Each of these aspects supports a sense of wellness within oneself, thereby supporting the first component of social wellness.

\section{Supporting Emotional Processing and Resilience}

Storytelling supports a child's emotional processing by providing an alternative experience where she can see her own situation lived in the experience of another. In this way, the experience is removed, or disconnected from the child, and it allows her to more fully work through the processing of her own challenge with a sense of objectivity and without personal judgment (Burrows, 2013; Nguyen, Stanley, Stanley, \& Wang, 2015; Schwartz 1997, 1999). This process of detaching from an experience and seeing it objectively allows for the untangling of the emotional response to the experience (Burrows, 2013). This is the process of positive emotional processing and developing resilience, both of which are healthy aspects of social wellness.

When a child hears tales of challenge, courage, and resolution, she feels hope within herself that she can also conquer challenges, face fears, and be courageous. More importantly, she is able to experience this sense of hope and confidence in moving forward without having to examine the challenges directly in their own situation, and the story presents a safe and indirect way to garner resilience (Perrow, 2008; Nguyen et al., 2015).

Along with the ideas of emotional processing and resilience, storytelling can support a child's healthy development of self-esteem and personal identity. McCaleb (2003) cites the use of story as medicine that provides "images of wholeness that can awaken and lead a person toward self affirmation of what is uniquely good and beautiful about his or herself" (p. 71). Nguyen and colleagues (2015) propose that "[s]torytelling can help people form new identities in times of conflict, recall old wisdom and transform endings to challenges in life" (p. 3), and the lessons learned through storytelling can "serve as a protective balm against the painful storms of life" (p. 3).

\section{Supporting Personal Meaning-Making}

Personal meaning making in large part is about how we learn what is appropriate and what our social, ethical, and moral values are. One of the subtle powers of storytelling is that it allows a child to make her own meaning of a situation and reach her own conclusions. That is, storytelling is an indirect, yet 
potent means of reaching a child in ways that are palatable and developmentally appropriate. Our very human experience is based on story and using the medium of storytelling allows for experiences to be shared and understood in ways that are non-threatening and removed from personal experience (Eder, 2010; Parker \& Wampler, 2006; Schwartz, 1997).

Davies (2007) suggests that storytelling aids in the development of a child's ability to interpret and understand events beyond her immediate experience, and these stories provide a positive and safe environment where she can learn lessons and discover truths in her own way (p. 5). In addition, Schwartz (1997) offers that in the school years, children's sense of self and personal responsibility is still dreamy and diffuse, as much "outside" themselves as "inside." Hearing themselves described in a purely imaginative and objective way helps children more than words that are directly spoken to them (p. 17). Sherman (2008) shares that, "wrapped in the sweet pill of an entertaining story, a moral goes down more easily" and allows for a message to be developed by "saying without saying" ( $p . x v i i i)$. A child, therefore, can best come to her own moral conclusions when ideas of morals and ethics are brought to her in an indirect manner, thereby allowing her to see the situation outside herself.

\section{Cultivating a Personal Connection}

It is not that a child cannot glean a similar experience from reading a story or having a story read aloud. In fact, the power of the written word is mighty. But storytelling, especially as I have described it here, offers an advantage over printed text because it is highly adaptable to any given situation. More importantly, I, as the class teacher, can have a strong sense of what the child is experiencing and what type of story will help bring an image or journey that will support that child's emotional processing.

Another benefit of sharing through storytelling, as opposed to text, is what Burrows (2013) describes in her research as an "atmosphere of understanding and empathy" created between teller and listener ( $p$. 180). Through storytelling, it appears to the child that the story originates in the teller. Therefore, the child can experience a strong and live connection with the teller and feel that the teller truly understands what the child is experiencing. Storytelling creates a direct and personal experience between the teller (teacher) and listener (child) through which a strong sense of personal connection and understanding is subtly, yet meaningfully, established.

\section{Storytelling and the Community}

I am fortunate enough to teach in a learning environment where I get to engage in storytelling with children almost every day, and I was eager to explore through this research what implication storytelling has on the community as a whole. Through my inquiry, I found that the practice of storytelling supports social wellness in the classroom community as a whole in three ways: first, it creates a shared, communal experience; second, it creates a relational experience; and third, it allows for a tailored, personalized experience. 


\section{A Communal Experience}

Storytelling draws children together into one shared, common experience. It offers an opportunity to experience and express feelings essentially in unison. Such communal, shared experiences are the heart of relationships (Davies, 2007). The importance of this point should not be overlooked. Storytelling creates an experience in which the class essentially lives and breathes, for at least a short period of time, as a single organic entity. Sherman (2008) proffers that

the most wonderful gift of storytelling is the bonding of a group. Held close under the spell of the story, the group breathes as one, and the shared experience softens the edges between individuals and brings everyone closer in the warmth of the moment. (p. xviii)

It is not often that this gets created in the classroom, and it is the power of storytelling that allows a group unity to emerge. Now extend that shared space that is created through storytelling to something more than curricular content. Imagine it as a place to work both pedagogically and holistically to build community and foster social wellness.

\section{A Relational Experience}

Storytelling is also relational. It promotes the building of relationship and is an intimate, yet impermanent experience between teller and listener. It is an experience that is both personal and temporary, with the promise to be re-created, but never in the exact same way. In this way, both teller and listener are cocreators in a unique experience of mutual creation (Abatan, 2011). Storytelling is both a shared and temporal occurrence in that it is brought for the class at a particular time and in a particular way, like a gift shared between teller and listener. Moreover, storytelling is not a lone experience as it must have both teller and listeners (Phillips, 2013); it is always a shared experience and the sharing of that experience builds relationship between teller and listener as well as among listeners, and in educational environments, that experience fosters relationship and community, a cornerstone of social wellness.

I reiterate the point that when a teacher engages in storytelling, it appears to the children that the teacher is not only living the story with them, but also embodies the knowledge, wisdom, and understanding shared through that story. Children feel they are being offered something directly from the teacher, not from an unknown author relayed by the teacher. It appears that the teacher is giving something of and out of herself, and indeed she is. The benefits of this relational experience are manifold, but two aspects in particular are of notable importance. First, children perceive the teacher as an authority who possesses wisdom and understanding, and this perception fosters trust and respect. Second, storytelling is direct communication where both teller and listeners are united in an experience in the true language of relationship (McCaleb, 2003). Storytelling, for both teller and listener, draws subtly, yet fundamentally, on the essence of our communication as human beings, including what it means to listen and what it means to speak. Storytelling creates a full experience in human communication, with nothing to interrupt the connection between teller and listener. Such personal and experiential opportunities create a level of intimacy, empathy, and unity that reinforce positive relationship (Berkowitz, 2011). 


\section{A Tailored Experience}

One of the great advantages of storytelling over sharing textual material is that storytelling allows for the teacher to tailor and personalize the story to meet the perceived needs or mood of any situation in the classroom. Davies (2007) speaks to the power of oral narrative as a tool entirely at the hands of the teacher: "I am the captain, and the ship is my story. I am taking the audience on a journey. I moved to the story, changing pace in style. In essence I'm free to do what I want, when I want" (p. 5). The flexibility and adaptability of storytelling allows a teacher to respond to nearly any situation in the classroom subtly, indirectly and imaginatively (Mellon, 1992).

In storytelling, a teacher must rely on careful, intuitive listening to read the needs of a given situation and then intentionally choose and tailor a story to match those circumstances. As a teacher considers a story to share with the class, it is important to keep in mind that it is not just the content of the story that matters, but just as essential is both the context and manner in which the story is shared (Eder, 2010).

\section{Toward a Practice of Holistic Storytelling}

Much is written in current educational literature about the place of storytelling in taking up curriculum (Davies, 2007; Egan, 1986), but there is a significant gap in the literature about the notion of holistic storytelling. I offer the idea of holistic storytelling as beyond storytelling brought with the aim of conveying curricular content, literacy instruction, value education, and the like. It is storytelling that nurtures soul capacities, identity, belonging, and overall social wellness.

An approach to education connected to social wellness reminds us to see each child as a whole human being as opposed to collection of specific characteristics or behaviours. Such a holistic perspective can also allow a teacher to see the class as a whole, an entity unto itself, instead of a summation of individual pieces. From this holistic perspective, both child and class community benefit by being seen in their entirety.

Inspired by other researchers exploring holistic professional practices (Kubsch et al., 2007; McEvoy \& Duffy, 2008), I offer the following definition in applying a holistic perspective to storytelling in the elementary classroom: Holistic storytelling embraces the mind, body, and spirit of each child as well as the whole class community, and creates a classroom environment that nurtures social wellness. Holistic storytelling is both child-centered and community-focused in order to provide enhanced wellness for both the child and the class community, caring for both as a whole and unified entity.

Holistic storytelling, therefore, is not one type of story or any set recipe. It is not simply the telling of a story to impart moral education or redirect behaviour, although those aspects can be included. Holistic storytelling is the practice of mindfully crafting and bringing stories to children with the intention to nurture a sense of social wellness within the community. By using storytelling in this way, I strive to 
support both child and community in a way that promotes a true social wellness, where what is cultivated is healthy children in a healthy environment.

\section{Reflections From Classroom}

In my own teaching practice, I find social wellness is fostered not just by the content of the story, but also by the very practice of regular storytelling. As I hope this article has illustrated, social wellness is a constellation of many aspects, and by practicing storytelling often these pieces are continually being tuned and refined. In reflecting on the ways in which I bring storytelling to children, I can point to two main impetuses: in the sharing of new learning content and for drawing attention to social issues. With the right story, both of these aspects are alive and active in one storytelling experience. Through the experience too, there is also the building of personal connection and an overall fostering of social wellness.

I have the privilege of teaching in a school where storytelling has a central place in our learning experiences. Most often storytelling is used to introduce new content, including presenting context and visual imagery to accompany that content. The story can be narrative or descriptive in nature, depending on the content. Fundamentally though, the storytelling experience plants the seeds for what will hopefully start to germinate in children in the following days in their learning. This allows curricular learning to be introduced and developed with children in ways that continue to pique their interest and build meaningful connections with the topic of study. Truly I feel it is through storytelling that I open the door for children to have a personal and soulful relationship with their learning, not just an intellectual experience.

When children are steeped in storytelling, they engage in it fully and effortlessly. It is therefore a seamless step to bring a story to children that is not about new content, but instead more focused on tuning an aspect of social wellness. Any teacher teaching any age of children can work with this idea by asking, what content can I bring to children that meets the development of their sense of self, including selfesteem and self-confidence, as well as how to understand their classmates better? For example, I used storytelling to present examples of a character (child, animal, or even otherwise, depending on the age) who faces a challenge or quest, which is indirectly a struggle with some sense of self or connection with others, and how that individual, and sometimes together with a group, find resolution. Stories of this nature reach the children in ways direct words could not, allowing them to see the situation outside themselves without any sense of shame or guilt. What I appreciate most about the use of storytelling in this way is that it allows me to personalize the story to what is happening in our community, bringing it in the most meaningful, yet subtle and indirect way.

One of the joys of working with storytelling is that I often cannot predict where the right story will emerge, and I offer an example to illustrate how I recently used storytelling for both presenting new content and supporting social dynamics. Earlier this year in our study of botany, I was sharing a story with the class 
that described the symbiotic relationship between conifer trees and mosses. This story was descriptive in nature, in that it was factually accurate from a scientific perspective, but also went beyond the factual content to present visual imagery and personal connection to enliven the content. It was a story that allowed the children to feel this symbiotic relationship, rather than me simply telling them about it or reading it in a text. Serendipitously, this learning came right at a time when I was looking for a way to support my class in being positive role models as older buddies to a group of younger children in the school. I revisited our story from botany about the conifers and the mosses, and this time I extended it allegorically, creating a story that painted my class as the protective guardian conifers and the younger child as the gentle mosses. Through this storytelling and the implied metaphor, I could actually see the children hold themselves a little more upright and embody that nurturing, protective force. This imagery brought to the children a vision of themselves to aspire to far more authentically than if I had just told them how and why to be positive older buddies.

The experience of storytelling goes well beyond its content, be it curricular or social in nature. Content becomes the medium for the experience that we share together. When children and I share a storytelling experience each day, there are several minutes of intense focus and careful listening that comes not from me directing it, but rather from shared expectation and unified experience. When we form this way together, without explicit instruction, but through mutual, respectful habit and anticipation, I can see reflected the healthy social cohesion of our community. It also reminds me that I need to bring them something worthy of this careful, collective listening.

The capacity for personal connection between teacher and child also goes beyond what I shared above. When I speak a story to children, they hear it as a lived, authentic experience, and once this becomes part of an established learning rhythm, it is hard to engage otherwise. I will confess that I did not fully appreciate this until one day, feeling not very prepared to tell a story well, I tried to read to children instead. I managed to get two sentences read from the page when I had no choice but to stop. There was no journey here we were starting together, no shared experience. It felt to me flat and empty compared to our usual sharing. I could not look children in the eyes as I spoke to them. There were no natural pauses, no places for emphasis, intonation, or embellishment. I could not redirect or linger in part of the story based on their reactions. In fact, it was as though I had disconnected myself not only from the content, but also from children. Compared to what I was used to, this experience was vacant and hollow. It was in this moment that I truly realized the potency of storytelling and what it brought to my experiences with children each day. I turned over the sheet I was reading, stepped away from the stand that held the story, and let whatever knowledge I had of the story originate from me, not the page. In doing so, I reestablished my connection not just with the content, but also, and more importantly, with the children. What I brought to them, and what they gave back to me, even in what I felt was a weak story, was stronger than anything I could have read off the page.

While I still feel like a novice storyteller, I now cannot imagine teaching children without the use of storytelling. I have told enough stories to children to know that no explanation is needed around the 
stories and the ideas implicit instead need to settle within them, allowing each child to let the experience live within them. And then, when I hear children getting ready for recess, sharing images and ideas from the story and taking them into their play, I know the power of the story is working within them.

\section{Conclusion}

Storytelling is an integral part of the human experience. While storytelling has a multitude of uses in pedagogical practices, my inquiry offers a unique perspective on storytelling as a means of supporting social wellness in an elementary classroom. Social wellness has the two fundamental components of being healthy in oneself and healthy in interactions with others. Therefore, in connecting social wellness and storytelling, I have examined the ways in which storytelling supports both the individual child and the class community as a whole, thereby exploring both aspects of social wellness.

A unique contribution of this research is the creation of the definition of holistic storytelling, which is storytelling used by the teacher in the classroom in a way that seeks to unify mind, body, and spirit of each child and thereby enhance social wellness for individuals and community alike. This type of storytelling seeks to reconnect with the original and fundamental essence of storytelling as a unifying, meaning-making experience in which we hope to understand ourselves and our relationships with each other.

My own inquiry feels as though it has just been a peek at the possibilities held within holistic storytelling. I have brought the perspective of such storytelling as originating with the teacher in an elementary classroom, but the potential reaches far outside this specific situation. How could such ideas be brought to children in early childhood education? Or in pedagogical work with adolescent and adult learners? Both Nguyen et al. (2015) and Horsely (2007) extend beyond learning environments and cite the place of storytelling as a positive support for language learners and immigrant communities. The possibilities for holistic storytelling extend well beyond the elementary classroom. Another potential consideration for future research is placing storytelling in the hands of children. In what different ways would this promote social wellness? What are the additional forms of media in which storytelling can be meaningfully shared?

Through the experience of storytelling we reconnect with our shared human experience. Through holistic storytelling, classrooms should become enhanced communities where children more consistently and more deeply feel a sense of social wellness. Moreover, it is not just within the classroom walls that children will feel open to and connected with each other. The sense of unity and commonality they gain from their enhanced sense of social wellness in the classroom, cultivated by storytelling, will hopefully follow them through their years of adolescence and adulthood. What started as a classroom community will continue and spread into new and larger communities, made up of individuals for whom community and others matter deeply. 
My own experience with storytelling continues to be a journey. It started with great trepidation, and to be honest, not entirely of my own choosing. However, I am grateful that I was challenged in this way, and every time I tell a story I appreciate the potential and power that is created through storytelling. This shared, lived experience with my class connects us in a deep and meaningful way, not only while the story is told, but also after. When I finish a story with children, I never end with "the end," because we have an unspoken recognition that it is not a truth. Rather, the magic of storytelling is that it creates a beginning. I hope my research has presented the possibility of new beginnings for fellow teachers in the craft of storytelling.

\section{References}

Abatan, O.L. (2011). The folklorist as teacher: Towards the use of storytelling pedagogy. Journal of Communication, 2(2), 125-130.

Agosto, D. (2013). If I had three wishes: The educational and social/emotional benefits of oral storytelling. Storytelling, Self, Society, 9, 53-76.

Berkowitz, D. (2011). Oral storytelling building community through dialogue, engagement, and problem solving. YC: Young Children, 66(2), 36-40.

Burrows, L. (2013). Transforming 'The red beast' within through mindfulness and therapeutic storytelling: A case study. Australian Journal of Guidance \& Counselling, 23, 172-184. doi:10.1017/jgc.2013.17

Carlson, R., \& Arthur, N. (1999). Play therapy and the therapeutic use of story. Canadian Journal of Counselling and Psychotherapy, 33, 212-226.

Retrieved from http://cjc-rcc.ucalgary.ca/cjc/index.php/rcc/article/view/142

Creswell, J. W. (2014). Research design: Qualitative, quantitative, and mixed methods approaches. 4th Ed. Thousand Oaks, CA: SAGE Publications, Inc.

Davies, A. (2007). Storytelling in the classroom: Enhancing traditional oral skills for teachers and pupils. London: SAGE Publications Inc. (US). Retrieved from http://www.ebrary.com

Eder, D. (2010). Life lessons through storytelling: Children's exploration of ethics. Bloomington, IN: Indiana University Press. Retrieved from http://www.ebrary.com

Egan. K. (1986). Teaching as storytelling: An alternative approach to teaching and curriculum in the elementary school. Chicago: University of Chicago Press.

Hanckel, J., \& Segal, L. (2016). The Inspir=Ed project: A holistic early childhood program for enhancing parent-child well-being. Childhood Education, 92, 10-21. doi:10.1080/00094056.2016.1134236

Horsely, K. (2007). Storytelling, conflict and diversity. Community Development Journal, 42, 265-269. doi:10.1093/cdj/bsm002

Kubsch, S., O’Shaughnessy, J., Carrick, J., Willihnganz, T., Henricks-Soderberg, L., \& Sloan, S. A. (2007). 
Acceptance of change in the healthcare paradigm from reductionism to holism. Holistic Nursing Practice, 21, 140-151. doi:10.1097/01.HNP.0000269151.88602.37

Kirkby, J., Faulkner, J., \& Perrin, J. (2014). 'Once there was a ...': Reclaiming storytelling in the middle years. Literacy Learning: The Middle Years, 22(2), i-x.

Land, K. (2007). Storytelling as therapy: The motives of a counselor. Business Communication Quarterly, 70, 377-381.

Leeming, D. A., \& Sader, M. (1997). Storytelling encyclopedia: Historical, cultural, and multiethnic approaches to oral traditions around the world. Phoenix, AZ: Oryx Press.

McCaleb, J. (2003). Story medicine. The English Journal, 93, 66-72. doi:10.2307/3650573

McEvoy, L., \& Duffy, A. (2008). Holistic practice - A concept analysis. Nurse Education in Practice, 8, 412-419. Retrieved from http://dx.doi.org/10.1016/j.nepr.2008.02.002.

Mellon, N. (1992). The art of storytelling. Rockport, MA: Element Books Inc.

Nguyen, K., Stanley, N., Stanley, L., \& Wang, Y. (2015). Resilience in language learners and the relationship to storytelling. Cogent Education, 2:991160. doi:10.1080/2331186X.2014.991160

Parker, T. S., \& Wampler, K. S. (2006). Changing emotion: The use of therapeutic storytelling. Journal of Marital \& Family Therapy, 32, 155-166.

Perrow, S. (2008). Healing stories for challenging behaviour. Gloucestershire, UK: Hawthorn Press.

Phillips, L. (2013). Storytelling as pedagogy. Literacy Learning: The Middle Years, 21(2), ii+.

Ratner, C. (2008). Methodological Holism Versus Individualism. In Lisa M. Given (Ed.), The Sage encyclopedia of qualitative research methods. (pp. 514-517). Thousand Oaks, CA: SAGE Publications, Inc. Retrieved from http://dx.doi.org.ezproxy.lib.ucalgary.ca/10.4135/9781412963909.n266

Schwartz, E. (1997). Why the setting sun turns red: And other pedagogical stories. Fair Oaks, CA: The Association of Waldorf Schools of North America.

Schwartz, E. (1999). Millennial child: Transforming education in the twenty-first century. Hudson, NY: Anthroposophic Press.

Schwartz, S. E. (2013). At the cost of your life: Social value, social wellness. EXPLORE: The Journal of Science and Healing, 9, 351-354. Retrieved from http://dx.doi.org/10.1016/j.explore.2013.08.009

Sherman, J. (2008). Storytelling: An encyclopedia of mythology and folklore. Armonk, NY: M.E. Sharpe.

University of Calgary (n.d.). Social Wellness. Retrieved from

http://www.ucalgary.ca/wellnesscentre/resources/guide/social

University of California (n.d.). Mind Body Wellness Challenge. Retrieved from http://wellnesschallenge.ucdavis.edu/social.html 
University of California, Riverside (n.d.). Social Wellness. Retrieved from

https://wellness.ucr.edu/social_wellness.html

University of New Hampshire Health Services (n.d.). Social Wellness. Retrieved from

http://www.unh.edu/health-services/ohep/social-wellness

Verschuren, P. J. M. (2001). Holism versus reductionism in modern social science research. Quality and Quantity, 35, 389-405. doi:10.1023/A:1012242620544

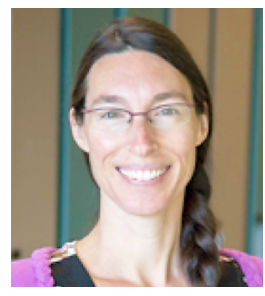

Rachel Tinckler is an elementary school educator in Calgary, Alberta, where she has taught in both public and private schools. She holds a Bachelor of Arts in Economics from Franklin and Marshall College, and a Bachelor of Education and Masters of Education, both from the University of Calgary. Her graduate course work focused on creativity, student confidence, professional leadership, and expressive writing and storytelling with children. She is in her tenth year of teaching and is inspired to enlivening and enriching curriculum through integrated studies, artistic infusion, and storytelling. 